\title{
REACTIVE POWER MANAGEMENT IN A GRID-CONNECTED PHOTOVOLTAIC POWER STATION: A CASE-STUDY
}

\author{
Emil CAZACU, Dan-Valeriu GROŞANU, Lucian PETRESCU \\ University POLITEHNICA of Bucharest, Faculty of Electrical Engineering \\ Splaiul Independentei 313, Sector 6 Bucharest, Romania \\ E-mail: emil.cazacu@upb.ro, dan_valeriu.grosanu@stud.electro.upb.ro, lucian.petrescu@upb.ro
}

\begin{abstract}
The paper presents an applicative study on the power quality and energy efficiency operation for a photovoltaic power station with an installed capacity of 8.5 MW. The various operating regimes of the main network elements within the investigated photovoltaic plant are qualitatively and quantitatively. The reactive power flow in the plant that is permanently connected to the grid is especially examined. Thus, the losses within the power transformers and medium voltage cables in the plant are calculated due to the imposed by the load (often deforming and unbalanced regimes). In this manner, opportunities are identified to increase the energy efficiency of the entire system but also methods to improve the quality of energy delivered at the point of its connection to the local energy system.
\end{abstract}

Keywords: power quality, reactive power, photovoltaic plant, power distribution transformer, convertors.

\section{INTRODUCTION}

The paper illustrates the full-time operation of an 8,5 MWp grid-connected photovoltaic power station, detailing its main working particularities especially regarding the circulation of the reactive power. Thus, different solutions are quantitatively investigated to establish the best method of power factor correction since the National Electric Power System (NEPS) in the plant connection locations accept values over 0.98 for the power factor (PF >0.98). The suggested solutions (procedures) are critically analyzed simultaneously considering their technical and economic aspects.

The schematic diagram of the main photovoltaic power plant component in normal (daylight) operation state is indicated in Figure 1. This reveals a typical schematic of a grid-connected solar power plant [1-8]. The here examined solar park has a power installed in photovoltaic panels of $8.48 \mathrm{MWp}$, comprising the main component:

$>35332$ photovoltaic panels of $240 \mathrm{~W}$ each, with $\mathrm{Vpv}$ $($ maximum power voltage $)=29.2 \mathrm{~V}(\mathrm{DC}), I_{\mathrm{mp}}$ (maximum power current) $=8.22 \mathrm{~A}(\mathrm{DC}), V_{\mathrm{oc}}$ (open circuit voltage) $=37.25 \mathrm{~V}(\mathrm{DC})$ and $I_{\mathrm{sc}}$ (short circuit current $)=8.78 \mathrm{~A}(\mathrm{DC})$. The technical data of the panels are presented in [9].

$>$ The installed power in the plant's inverters is 8.03 MW. The inverters used for the construction solution are produced by Power One (currently
Fimmer Italy) and their technical data of are given by the manufacturer and illustrated in [10].

$>$ The electrical power transformers in the photovoltaic power station are ONAN sealed type three-phase oil transformer for rectifier operation Insulation Class A (equipped with oil, temperature, and gas level sensors) and are transformers with low vacuum and load losses. The solar plant contains 6 such transformers of $1600 \mathrm{kVA} / 20 / 0.32 \mathrm{kV}$, produced by Schneider Electric. The technical data of the transformers are exposed in [11].

$>$ The medium voltage (MV) cable that connects the solar park, has a length of about $10 \mathrm{~km}$. It is produced by ICME ECAB SA Romania. The cable is type A2XS (FL) 2Y1X 400/16, made of Aluminum and has a cross section of $400 \mathrm{~mm}^{2}$ and the screen made of Copper with $16 \mathrm{~mm}^{2}$, with a longitudinal and transverse water protection barrier. The technical data of the cable provided by the manufacturer are presented in [12].

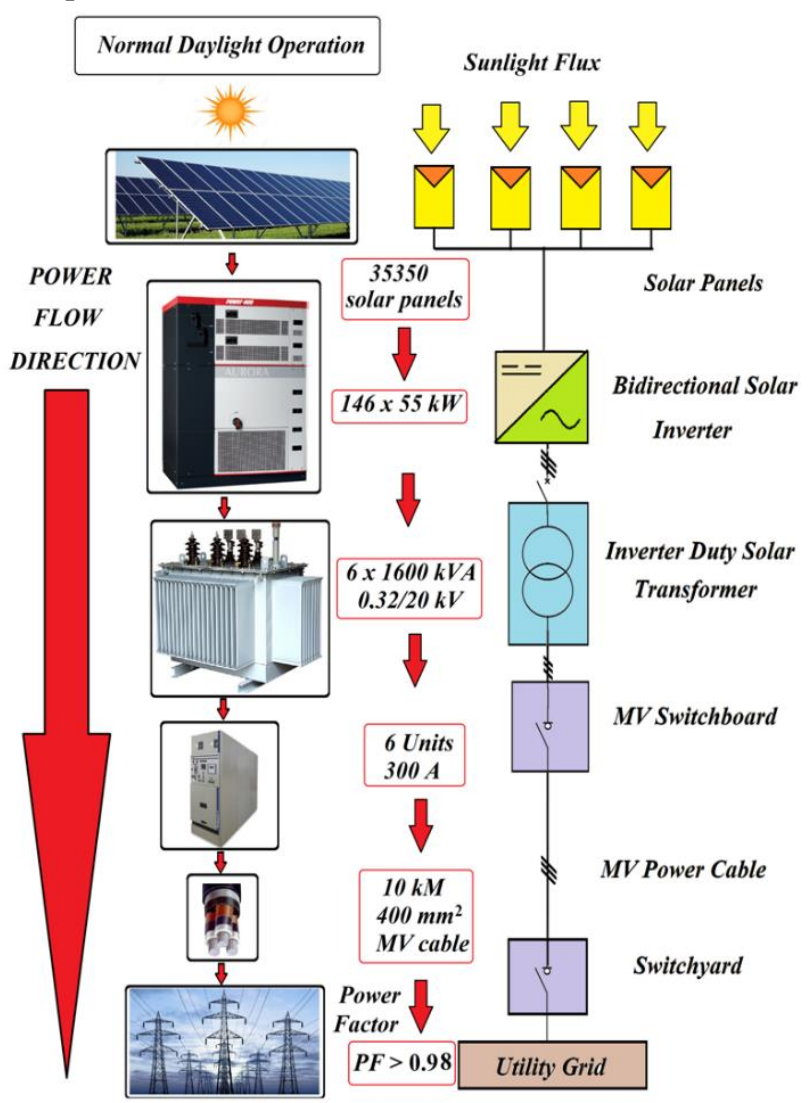

Figure 1: The schematic diagram of the main photovoltaic power plant components in normal operation state. 


\section{THE MEASURED POWER QUALITY PARAMETERS}

The measurements were performed on the low voltage (LV) side of the electrical transformers from 16.07.2021 to 27.07.2021, where the most important power quality parameters were visualized and critically analyzed. Two power quality instrumented were used for performing these measurements: Fluke 435 and Chauvin Arnoux CA 8335 Qualistar Plus [13, 14]. These apparatuses were also equipped with their corresponding detachable ammeter clamps for measuring the intense currents that could reach up to $2.5 \mathrm{kA}$ and voltage testers for measuring the voltages common values up to $320 \mathrm{~V}$. Furthermore, these measured data are acquired and transfer to a computation system that performed different analysis and visualization Figure. 2. Since the solar park has 6 identical $1600 \mathrm{kVA}$ transformers with similar load characteristics, the measurements results are illustrated only for one transformer - Figure. 3.

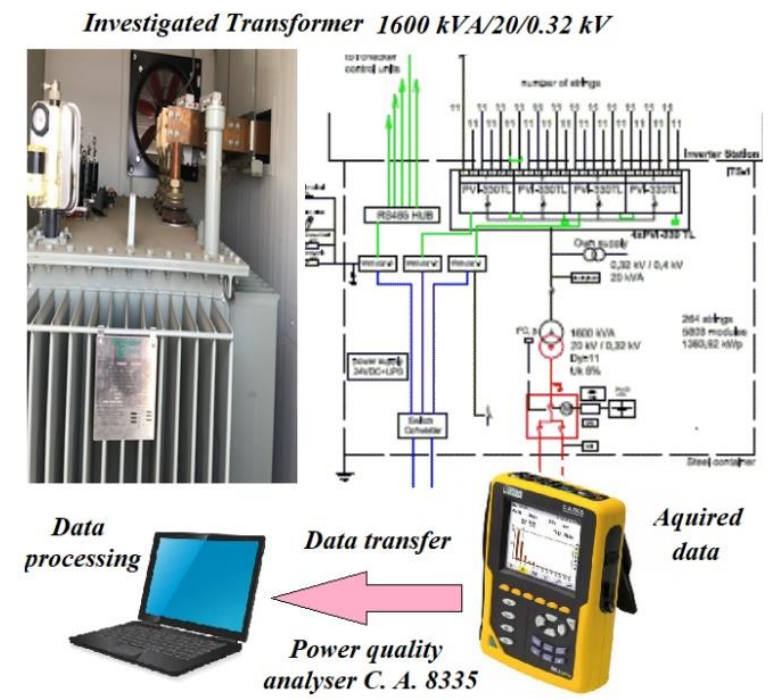

Figure 2: The investigated transformer and power quality data measurement location.

The most important parameters for both the voltage and the current are root mean square (RMS), Total Harmonic Distortion (THD), unbalance factor ( $V_{\text {unb }}$ and $\left.A_{\text {unb }}\right)$ and the powers (active, reactive, and apparent) circulated through the transformer [15-19]. According to their values, presented in Figure 3, the transformer operates under normal condition (daylight operation).

As one can notice, the phase shift of the current compared to the phase voltages is shifted by about 180 degrees, because the power plants are considered current generators; photovoltaic power plants synchronize with the mains voltages (in our case $20 \mathrm{kV} \mathrm{A.C)}$ ) and generate the overall electricity in the following direction: panelsinverters - transformers - NEPS (National Electric Power System) connection cable. The measured THD factors show that they can reach a value up to $25 \%$ in some cases, due to the appearance in the distribution network of some important high nonlinear loads (in the $20 \mathrm{kV}$ network are extraction pumps from the local oil industry powered by variable-frequency drives).
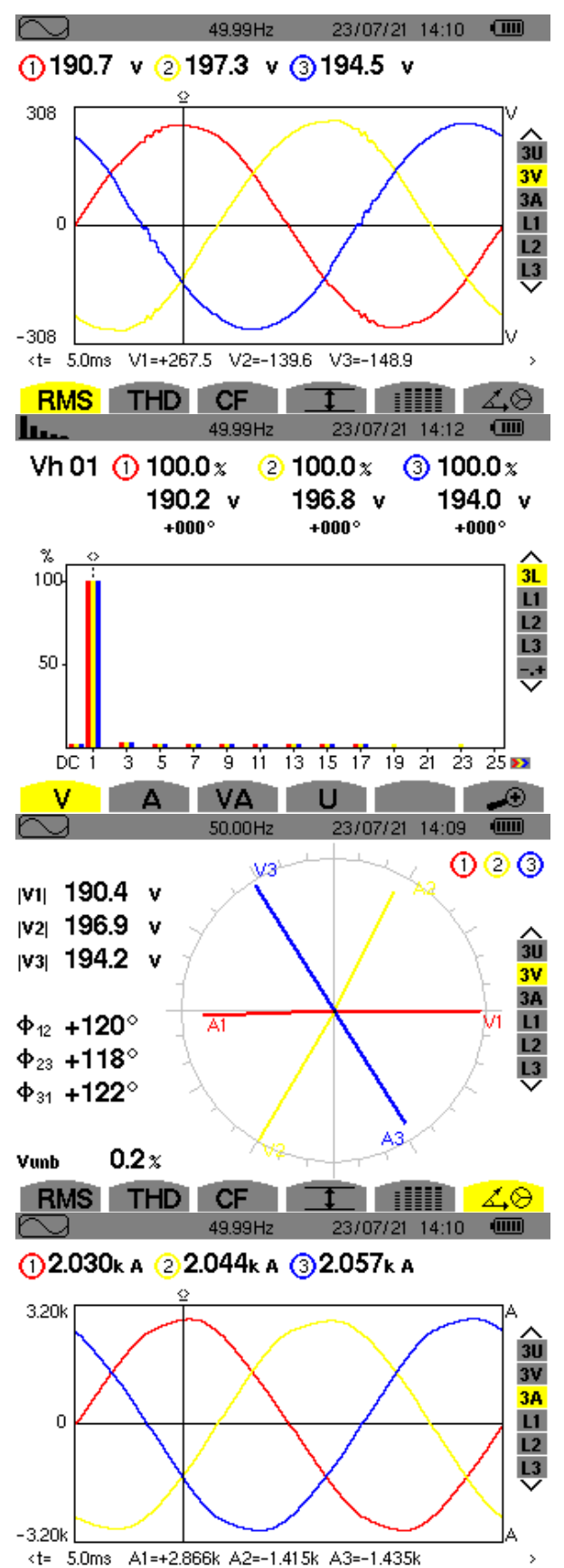

RMS THD CF I I 舴 $\measuredangle \theta$

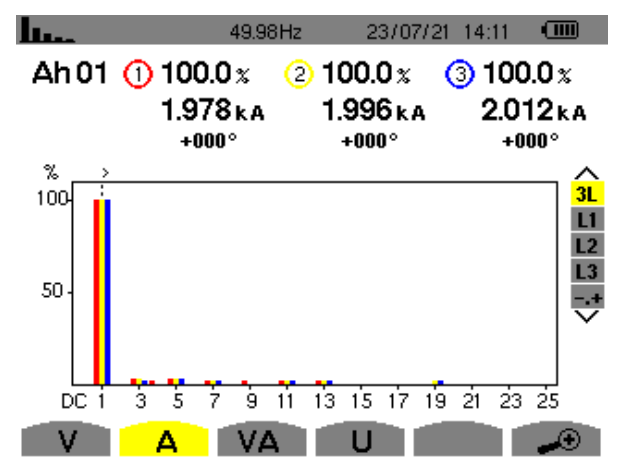



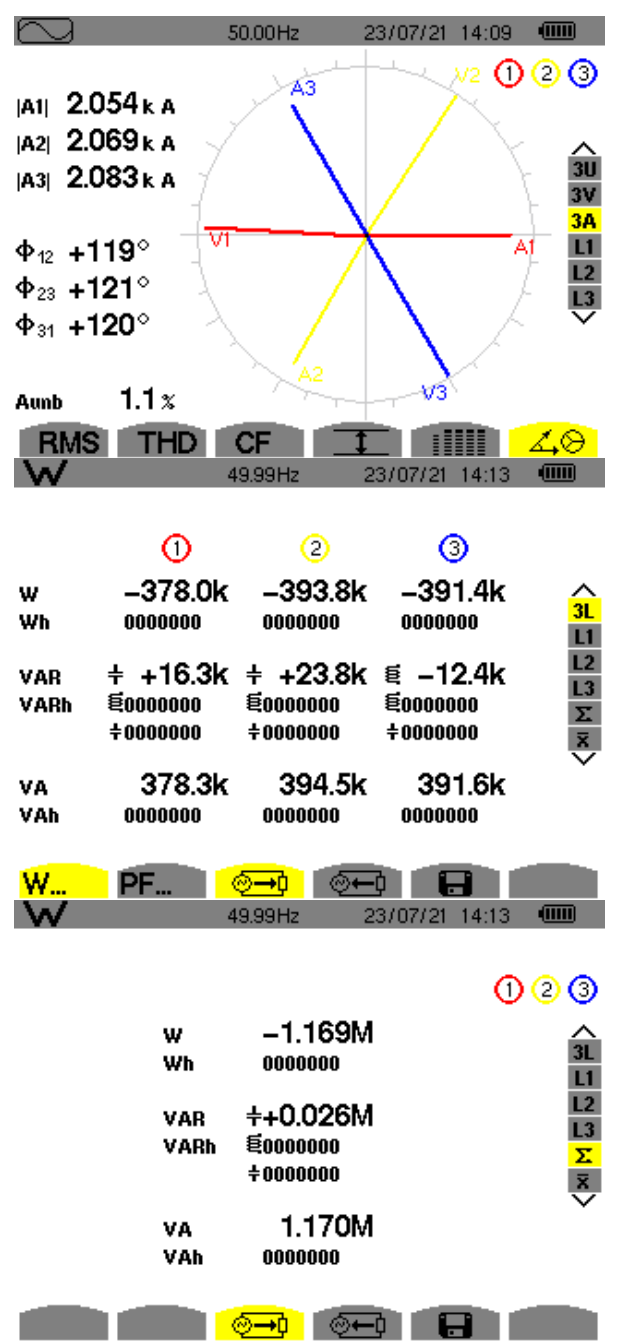

Figure 3: The main power quality parameters measured at the low-voltage side of one the transformer from the photovoltaic plant.

Also, the variation of some of these power quality parameters $\left(P, Q, P F, T H D_{i}\right)$ in the established measurement time-interval (from 16.07.2021 until 27.07.2021) were also monitored -Figure 4.

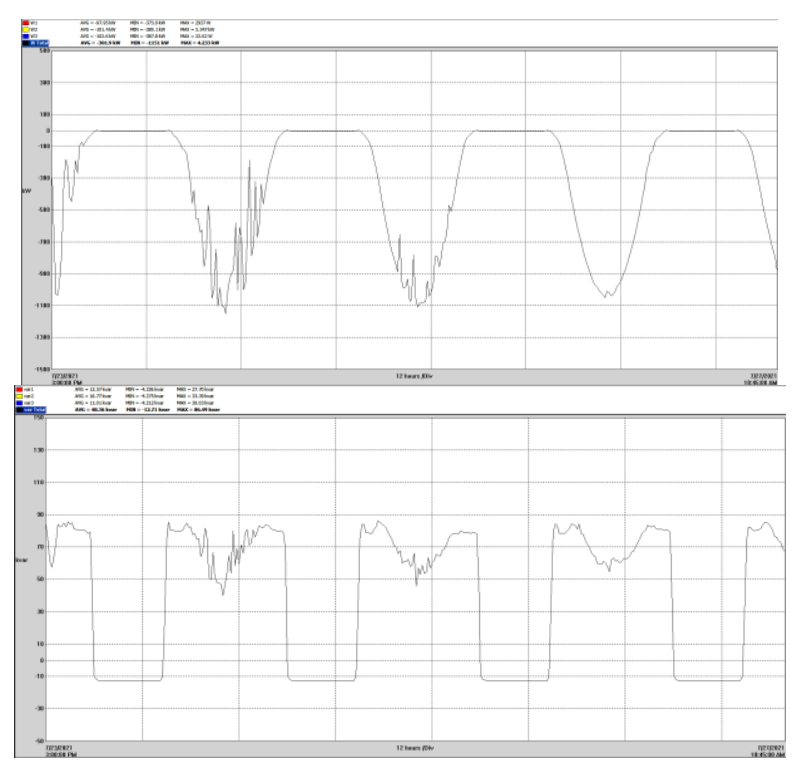

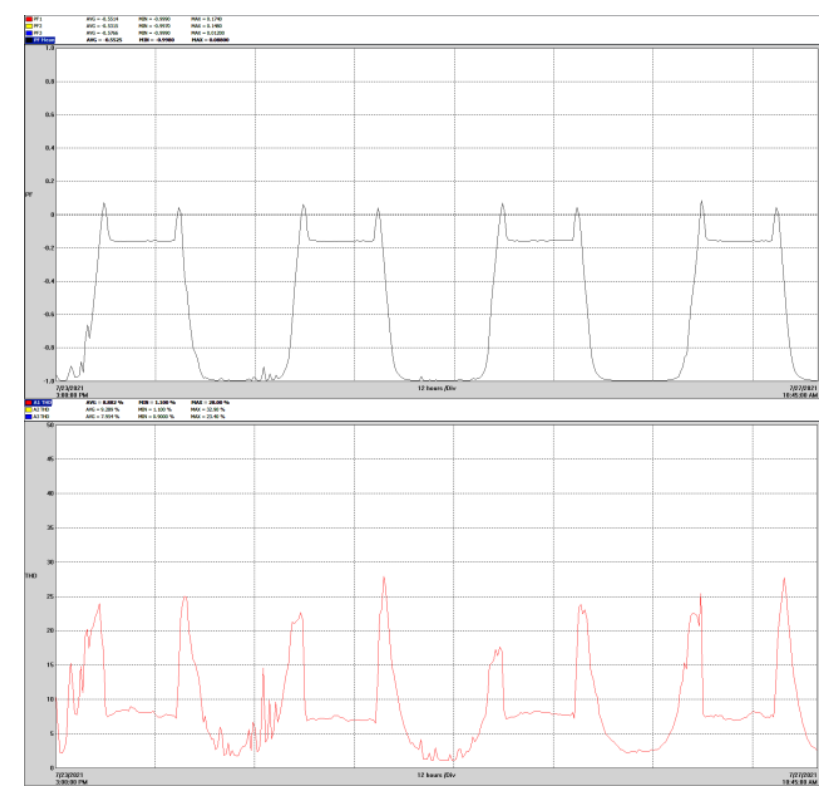

Figure 4: The main power quality parameters variation within the monitorization time interval.

\section{THE SOLAR PLANT INTERNAL NETWORK POWER LOSSES}

\subsection{Transformer Power Losses}

One of the major sources of the transformer heating is the losses within the machine. The latter depends on the transformer load factor, defined as the operating apparent power $S$ (measured at the low-voltage side) relative to its rated value $S_{n}$. Considering the voltage practically constant; one may write [11]:

$$
\beta=\frac{S}{S_{n}} \approx \frac{S_{2}}{S_{2 n}}=\frac{1170}{1600}=0.73,
$$

with $S_{2}$ and $S_{2 n}$ are the operating and rated apparent power of the transformer (at its secondary or LV side).

The transformer active $\Delta P_{T}$ and reactive $\Delta Q_{T}$ power losses, as well as of the network absorbed active powers are determined in respect of the load factor $\beta$ and the active power measured at the transformer low-voltage side [15-18]:

$$
\left\{\begin{array}{l}
\Delta P_{T}=\Delta P_{0}+\beta^{2} \Delta P_{s c}=9.16 \mathrm{~kW}, \\
\Delta Q_{T}=\Delta Q_{0}+\beta^{2} \Delta Q_{s c}=119 \mathrm{kVAR},
\end{array}\right.
$$$$
\text { with : }
$$

$$
\left\{\begin{array}{l}
\Delta Q_{0} \cong i_{0}[\%] S_{n}=68 \mathrm{kVAR}, \\
\Delta Q_{s c} \cong u_{s c}[\%] S_{n}=96 \mathrm{kVAR},
\end{array}\right.
$$

where $\Delta P_{0}, \Delta Q_{0}$ and $\Delta P_{\mathrm{sc}}, \Delta Q_{\mathrm{sc}}$ are the no-load and short circuit active and reactive losses, respectively. The variation of active and reactive power losses within the transformer in respect with the load factor are indicated in Figure 5. 


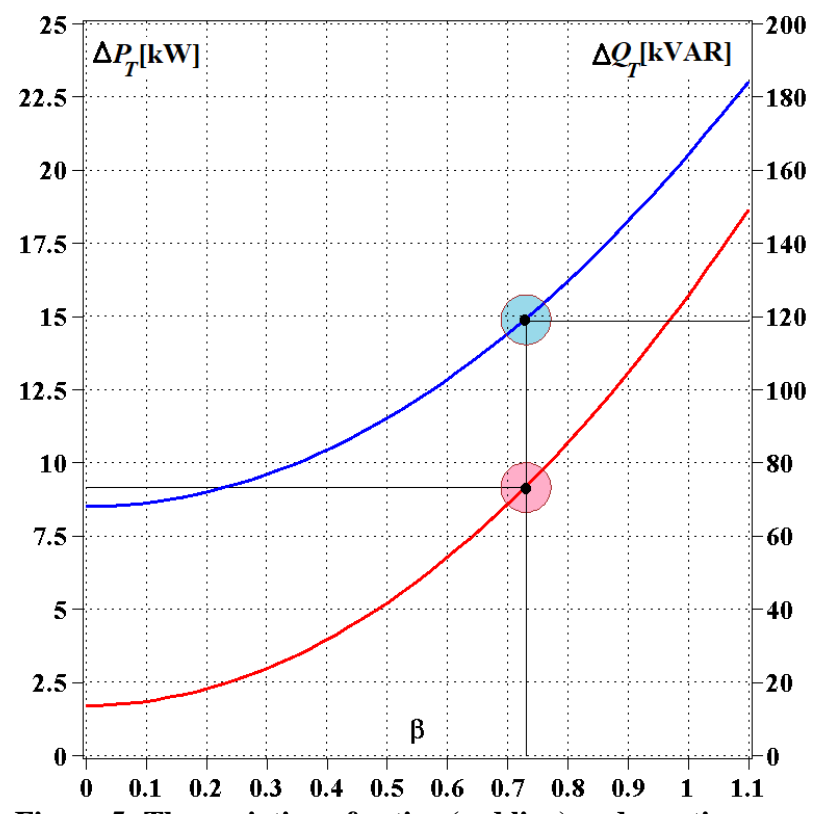

Figure 5: The variation of active (red line) and reactive (blue line) power losses within the transformer in respect with the load factor $\beta$.

\subsection{Medium Voltage Cable Power Losses}

The photovoltaic power station connection to NEPS, (realised by a switchyard with $20 / 110 \mathrm{kV}$ transformer station), is located approx. $10 \mathrm{~km}$ from the solar park. The connection line between the solar plant and the utility grid is acomplished by an underground medium voltage cable 2/20kV A2XS (FL) 2Y1x400_16 400mm².

The active losses within the cable at verious load factors (values of the active transported power) of are presented in Table 1.

Table 1. The active losses within the cable

\begin{tabular}{|c|c|c|c|c|c|}
\hline $\begin{array}{c}\mathrm{S} \\
{\left[\mathrm{mm}^{2}\right]}\end{array}$ & $R[\mathrm{Ohm}]$ & $I[\mathrm{~A}]$ & $\begin{array}{c}P \\
{[\mathrm{~kW}]}\end{array}$ & $\begin{array}{c}\text { Cable } \\
\text { losses } \\
P_{\mathrm{c}} \\
{[\mathrm{kW}]}\end{array}$ & $\begin{array}{c}\text { Cable } \\
\text { losses } \\
P_{\mathrm{c}} \%\end{array}$ \\
\hline 400 & 0.78 & 245.66 & 8,500 & 141 & 1.66 \\
\hline 400 & 0.78 & 144.51 & 5,000 & 48 & 0.98 \\
\hline 400 & 0.78 & 86.71 & 3,000 & 17 & 0.59 \\
\hline
\end{tabular}

One can notice that the active $P_{c}$ active power losses within the $400 \mathrm{~mm}^{2} \mathrm{MV}$ cable is not significant.

The reactive power circulated through the cable $Q_{c}$ can be estimated by taking into account the the service capacitiy of the cable $C=0.40 \mu \mathrm{F} / \mathrm{km}$. This value will generate over $500 \mathrm{kVAR}$ (at rated voltage $20 \mathrm{kV}$ ), which practically, represent the major reactive power of the solar plant. The MV cables within the solar park that connect the 6 transformer stations, have a cross section area of $240 \mathrm{~mm}^{2}$ and an aproximative length of $2 \mathrm{~km}$. Basic computation indicates that the reactive power generated by these internal cables of the solar park is practically compensated by the transformer coils.

Accordingly, the MV cable of cross section $400 \mathrm{~mm}^{2}$ and $10 \mathrm{~km}$ length is the main reactive power generator of the photovoltaic power plant.

\section{THE REACTIVE POWER MANAGEMENT WITHIN THE SOLAR PLANT}

To determine the capacitive reactive power to be compensated, the load curves measured by the power quality analyzers at the solar plant connection point to NEPS were used. This calculation method is not accurate because the cable length is approximated, and the transformers inductors values are not precisely indicated by the manufacturer. The main target (imposed by NEPS) is to achieve the "full-compensation" expressed by zero capacitive reactive power and a minimum inductive power factor of 0.98 .

During the day, in normal operation (Figure 1), the solar plant operates in "generator" mode - all transformers are supplied on low-voltage (LV) side $(0.320 \mathrm{kV})$ and generate on medium voltage side $(20 \mathrm{kV})$. In this situation, the power factor compensation was achieved naturally by adjusting the inverters in such a manner that at the connection point, an inductive power factor of $\mathrm{PF}=$ $0.98 \div 1$ is achieved. Obviously, the setting can also change to capacitive state but values of max. $30 \mathrm{kVAR}$ (capacitive) are acceptable. This is to consider due to the rapid variation of power load, which cannot be followed instantly by the control loop of the inverters.

During the night, the solar park is a capacitive type of load and operates in the "receiver" mode. All transformers are powered from the connection point of the NEPS (at their MV side) and the solar panels are "powered" by converters (which are in controlled "rectifier" mode suppling a low load). The active power consumed by the plant is about $40-50 \mathrm{~kW}$ being determined exclusively by empty transformer losses and auxiliary services transformer cabins (heating, lighting, etc.). The following solutions have been developed to ensure the compensation of the power factor:

1. The first solution is to set the inverters to operate in controlled rectifier mode by adjusting their switching angle to generate an inductive state of the solar plant and consequently to compensate all the reactive power generated by the cables. In this way the panels are powered by $500 \mathrm{~V}$ DC. This solution, however, causes over time a phenomenon of solar panels degradation due to their DC energization by inverters known as "PID" (Potential Induced Degradation). This manifests by degrading the solar panels material and electrochemical properties and finally by reducing the power generated by the solar park ("blackening of the panels") [20-22].

2. The second solution is to stop the inverters during the night and mount directly on the LV side of each transformer systems of three-phase compensation coils (star connected) - Figure 6. The coils are dimensioned at a power of approx. $10 \%$ of the rated transformer power resulting in $160 \mathrm{kVAR}$ inductive (a total $550 \mathrm{kVAR}$ for the six transformers). They are to be automatically disconnected during the operation of the panels (when the luminous flux appears in the morning), and the solar plant switches to generator mode. Otherwise, in normal (daylight) operating mode of the solar park, they became very hot due to high current that cross their windings. 


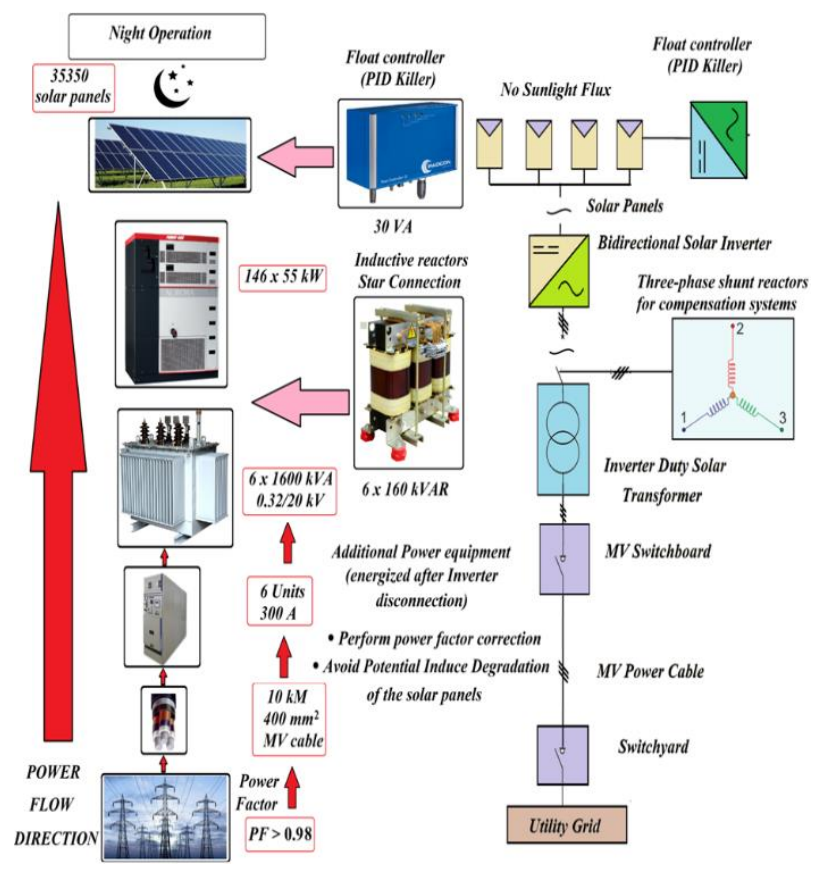

Figure 6: The schematic diagram of the main photovoltaic power plant components during the night operation.

In addition to the capacitive reactiv power compensation, it is also proposed to regenerate the properties of the damaged panels (due to their power supply by the inverters that provided compensation during the night) [23-29]. Thus, when the inverters are disconnected from the circuit the solar panels are powered by special converters called float controller or PID Killer. The latter apply a reverse voltage to the photovoltaic panels of about $875 \mathrm{~V}$ (DC), causing a restoration of about $80 \%$ of their initial properties ("whitening of the panels").

The system is fully automated and float the controllers monitor the voltage on the DC side and when it is close to zero (no light flux - at night) connects the PID killers and applies the reverse regeneration voltage on the solar panels.

Oviously, the second solution for the capacitive reactive power compensation was selected, resulting in a proper operation of the solar park and achiving significant savings compared to the replacement of degraded panels with new ones.

\section{CONCLUSIONS}

The power quality and energy efficiency analyses performed over the analyzed solar plant revealed that an optimal load factor of transformers is about 0.7 . Supplementary, no power quality parameter exceeded its maximal acceptable value ensuring a well operation of the plant in all the examined steady-state (night and day operation).

Due to the length of the medium voltage cable route from the plant to the NES connection point (about $10 \mathrm{~km}$ ), a capacitive reactive power flow in the connection station of 20/110 kV was generated. Initially, to impose a power factor of PF > 0.98, an adjustment loop was imposed to the commands of the inverters, enabling them to work in an inductive state. Unfortunately, analyzing for a long time the operation of the plant (from 2013 to actual date 2021) it was found, that due to the special operation the inverters at night, a reduction of nominal generated power of the solar panels was observed (during the day).

The occurrence of this phenomenon, known as Potential Induced Degradation (PID) was avoided by disconnecting the inverters and passively compensating the capacitive reactive power of the plant (mainly generated by medium voltage cable) by using special design inductive reactors. They are connected at the transformers secondary part during the night. Supplementary, PID killer converters (float reactors) were mounted during the night, managing to restore the damaged solar panels at almost $80 \%$ at their initial capacity. Economical estimations also indicates that in this manner, the solar panels life is increased, and the costs associated with the PID killer acquisitions are quickly recovered.

The evaluations of the operating efficiency of all the equipment used for the solar parc is very high as the computations revealed. Therefore, the system is an optimized one that has reached its technological limit in terms of energy efficiency.

Other alternative solutions to the power factor correction issue could be medium voltage compensation (still very expensive) and the usage of "PID-free" solar panel. The latter are to be consider at the first scheduled modernization process.

\section{APPENDIX}

The main parameters of the transformers used the photovoltaic power station are presented in Table 2 .

Table 2. Technical data of the solar plant transformers

\begin{tabular}{|l|c|}
\hline Transformer data & Value \\
\hline Rated power $(S n)$ & $1600 \mathrm{kVA}$ \\
\hline $\begin{array}{l}\text { Rated voltage from the primary } \\
\text { winding }\left(U_{l n}\right)\end{array}$ & $20 \mathrm{kV}$ \\
\hline $\begin{array}{l}\text { Rated voltage from the secondary } \\
\text { winding }\left(U_{2 n}\right)\end{array}$ & $0.32 \mathrm{kV}$ \\
\hline $\begin{array}{l}\text { Rated current in the primary } \\
\text { winding }\left(I_{l n}\right)\end{array}$ & $286.9 \mathrm{~A}$ \\
\hline $\begin{array}{l}\text { Rated current in the secondary } \\
\text { winding }\left(I_{2 n}\right)\end{array}$ & Dy 11 \\
\hline Transformer vector group & $1,7 \mathrm{~kW}$ \\
\hline No load power losses $\left(\Delta P_{0}\right)$ & $4.25 \%$ \\
\hline Rated short-circuit losses $\left(\Delta P_{s c}\right)$ & $6 \%$ \\
\hline The magnetizing current $\left(i_{0}\right)$ & \\
\hline The short-circuit voltage $\left(u_{s c}\right)$ & $\mathrm{kW}$ \\
\hline
\end{tabular}

\section{ACKNOWLEDGMENTS}

This work has been supported by the Competitiveness Operational Program 2014-2020 (COP), through the project ID/Cod My SMIS: 121611, contract number 273/24.06.2020 (acronym: SIPAMASRE). 


\section{REFERENCES}

[1] S. Ould Amrouche, S. Bouchakour, A. Hadj Arab, K. Abdeladim, F. Cherfa and K. Kerkouche, "Reactive power issues in grid connected photovoltaic systems, Int. Conference on Nuclear and Renewable Energy Resources, Antalya, Turkey, 26-29 Oct. 2014, pp.1-6

[2] A. F. Kadir, H. Mupangat, D. Mat Said and Z. Rasin, "Reactive power analysis at solar power plant" Jurnal Teknologi, vol. 83, no. 2, pp. 47-55, 2021, doi.org/10.11113/jurnalteknologi.v83.15104.

[3] B. P. Singh, S. K. Goyall and S. A. Siddiqu, "Grid Connected-Photovoltaic System (GC-PVS): Issues and Challenges" IOP Conf. Series: Materials Science and Engineering 594 (2019) 012032, IOP Publishing, doi:10.1088/1757-899X/594/1/012032.

[4] L. Jin, X. Gong, Q. Sun and M.o Sha, "Reactive Power Control of Grid-Connected Photovoltaic Power Generation" Journal of Physics: Conference Series 1754 (2021) 012001, IOP Publishing, doi:10.1088/17426596/1754/1/012001

[5] A. Dhaneria, "Grid Connected PV System with Reactive Power Compensation for the Grid," 2020 IEEE Power \& Energy Society Innovative Smart Grid Technologies Conference (ISGT), 2020, pp. 1-5, doi: 10.1109/ISGT45199.2020.9087728.

[6] G. M. Tina and G. Celsa, "Active and reactive power regulation in grid-connected PV systems," 2015 50th International Universities Power Engineering Conference (UPEC), 2015, pp. 1-6, doi: 10.1109/UPEC.2015.7339821.

[7] P. González, E. Romero, V. M. Miñambres, M. A. Guerrero and E. González, "Grid-connected PV plants. Power quality and technical requirements," 2014 Electric Power Quality and Supply Reliability Conference (PQ), 2014, pp. 169-176, doi: 10.1109/PQ.2014.6866804.

[8] D. Ibram and V. Gueorgiev, "Control of Reactive Power of a Single-Phase Photovoltaic Inverter," 2020 12th Electrical Engineering Faculty Conference (BulEF), 2020, pp. 1-4, doi: 10.1109/BulEF51036.2020.9326067.

[9] Electrical characteristics of Polycrystalline Silicon Solar panel ET Solar Group ET-P660240 (240W).

[10] Technical specifications PVI $55 \mathrm{TL}$ an PVI 55.0.TL Inverters - Power ONE - Italy (actual factory is Fimer Italy);

[11] Technical specification of Three-Phase Oil Transformer acc. DIN EN 60076-1 for Rectifier Operation 1600 kVA/ 20/0.32 kV, type: RCU 4234, Schneider Electric

[12] Medium voltage cable catalog ICME ECAB SA Romania, cable type 12/20kV A2XS(FL)2Y1x400_16 400mm².

[13] *** Fluke 435 - IEC Class A - Three-Phase Power Quality Analyzer - User Manual, Fluke Corporation, 2010.

[14] *** C.A 8335 Qualistar Plus - Three-phase electrical networks analyzer - Operating manual, Chauvin Arnoux Corporation, 2008.

[15] C. Sankaran, Power Quality, New York: CRC Press, 2002.

[16] M. A. S. Masoum, E. Fuchs, Power Quality in Power Systems and Electrical Machines, 2nd Ed. Elsevier Academic Press, 2015.

[17] J. D. Glover, T. Overbye, M. S. Sarma, Power System Analysis and Design, Cengage Learning, 6 ${ }^{\text {th }}$ Ed., 2016.

[18] L. Zhou and Y. Chao, "The research of reactive power control strategy for grid-connected photovoltaic plants," 2013 World Congress on Sustainable Technologies (WCST), 2013, pp. 12-17, doi: 10.1109/WCST.2013.6750396.

[19] H. Li, S. Liu, S. Lu, L. Chen, X. Yuan and J. Huang, "Reactive power optimization of distribution network including photovoltaic power and SVG considering harmonic factors," 2017 International Conference on High Voltage Engineering and Power Systems, 2017, pp. 219224, doi: 10.1109/ICHVEPS.2017.8225946.

[20] Y. R. Golive et al., "Analysis of Field Degradation Rates Observed in All-India Survey of Photovoltaic Module Reliability 2018," in IEEE Journal of Photovoltaics, vol. 10, no. 2, pp. 560-567, March 2020, doi: 10.1109/JPHOTOV.2019.2954777.

[21] S. Guo et al., "Investigation of Efficiency for PID-Affected Solar Module at Nonstandard Test Conditions," 2017 IEEE 44th Photovoltaic Specialist Conference (PVSC), 2017, pp. 1873-1876, doi: 10.1109/PVSC.2017.8366013.

[22] J. Oh, G. TamizhMani, S. Bowden and S. Garner, "Application of flexible glass to prevent PID in PV modules," 2015 IEEE 42nd Photovoltaic Specialist Conference (PVSC), 2015, pp. 1-4, doi: 10.1109/PVSC.2015.7355701.

[23] PADCON - Float Controller CI- Data Sheet CI 30.

[24] S. T. Lee and H. A. F. Almurib, "Control techniques for power converters in photovoltaic hybrid energy storage system," 3rd IET International Conference on Clean Energy and Technology (CEAT) 2014, 2014, pp. 1-6, doi: 10.1049/cp.2014.1494.

[25] J. Chang, H. Wang, H. Yang, J. Zhang and J. Huang, "The real situation of potential-induced degradation in multicrystalline silicon photovoltaic power plant," 2016 IEEE 43rd Photovoltaic Specialists Conference (PVSC), 2016, pp. 1682-1685, doi: 10.1109/PVSC.2016.7749910.

[26] A. Khaled, H. Aboubakeur, B. Mohamed and A. Nabil, "A Fast MPPT Control Technique Using PID Controller in a Photovoltaic System," 2018 International Conference on Applied Smart Systems (ICASS), 2018, pp. 1-5, doi: 10.1109/ICASS.2018.8652062.

[27] Yan Wang, Li Ding and Nan Li, "The application of fuzzy parameters self-tuning PID controller in MPPT of photovoltaic power system," Proceedings 2011 International Conference on Transportation, Mechanical, and Electrical Engineering (TMEE), 2011, pp. 1129-1132, doi: 10.1109/TMEE.2011.6199403.

[28] G. P. Modak and V. P. Dhote, "Study and analysis of zeta converter fed by solar photovoltaic system using PID controller," 2017 International Conference on Innovative Research In Electrical Sciences (IICIRES), 2017, pp. 1-7, doi: 10.1109/IICIRES.2017.8078313.

[29] T. Suyata and S. Po-Ngam, "Simplified active power and reactive power control with MPPT for three-phase gridconnected photovoltaic inverters," 2014 11th International Conference on Electrical Engineering/Electronics, Computer, Telecommunications and Information Technology (ECTI-CON), 2014, pp. 1-4, doi: 10.1109/ECTICon.2014.6839804. 